\title{
Caracterização dos argilominerais usados em matéria-prima cerâmica, da formação Rio do Rasto, Bacia do Paraná, no município de Turvo, SC
}

\author{
(Characterization of clay minerals used in the ceramic industry, from Rio \\ do Rasto formation, Paraná basin, exploitation in Turvo, SC, Brazil)
}

\author{
J.A. Costa, A.S. Mexias, M.E.B. Gomes \\ Instituto de Geociências da Universidade Federal do Rio Grande do Sul, Av. Bento Gonçalves 9500, Bairro \\ Agronomia, Porto Alegre, RS 91501-970 \\ jorge.costa@ufrgs.br,andre.mexias@ufrgs.br,marcia.gomes@ufrgs.br
}

\begin{abstract}
Resumo
No sudeste de Santa Catarina existem inúmeras minas de exploração de argilas destinadas à indústria cerâmica da região. Para o conhecimento desta matéria prima foi realizada a caracterização em detalhe de uma frente de lavra em atividade. A exploração é realizada em terrenos sedimentares da Formação Rio do Rasto (Permiano Superior) na Bacia do Paraná que afloram como morros testemunho. Foram coletadas quatorze amostras representativas dos níveis desta mina composta de argilitos com intercalação de siltitos de pequena espessura. As amostras foram analisadas por difratometria de raios X pelo método do pó na rocha total e na fração $<4 \mu \mathrm{m}$. A composição química foi determinada por fluorescência de raios X. Foram realizadas observações ao microscópio eletrônico de varredura (elétrons secundários) de fragmentos das amostras e microanálises por microssonda eletrônica de lâminas delgadas. Os resultados mostraram uma grande variação vertical da mineralogia, tendo sido identificados três níveis diferentes. Até 2,00 m há predomínio de esmectita. Entre 2,00 m e 5,50 m a esmectita é o principal argilomineral, mas com quantidade significativa de ilita/mica, e acima de 5,50 m há grande aumento do feldspato potássico e mica detrítica. Estudos de detalhe por difratometria de raios X (determinação do parâmetro b) e microanálises WDS por microssonda eletrônica permitiram identificar como montmorilonita a espécie argilomineral do grupo das esmectitas.

Palavras-chave: indústria cerâmica, argilominerais, caracterização mineralógica.
\end{abstract}

\begin{abstract}
In the southeastern part of Santa Catarina state, Brazil, many mines of clays used as raw material for the ceramic industry are found. A detail study of this material was developed in a mine in activity. The exploitation of clays is held in sedimentary rocks of Rio do Rasto Formation (Upper Permian) in the Paraná Basin. The outcrops are in hills testimonies. Fourteen samples were collected and represent the levels of this mine which consisted of argillites with intercalation of slim siltite layer. These samples were analyzed by X-ray diffraction using the powder method and in the fraction $<4 \mu \mathrm{m}$. The chemical composition was determined by X-ray fluorescence spectrometer. Petrographic observations in thin section were also performed. Scanning electron microscope images was obtained in samples fragments by secondary electron method. Electron microprobe microanalysis was performed in one thin section. The results showed large vertical variation in the mineralogy and it has been identified three different levels. Up to $2.00 \mathrm{~m}$ there is a predominance of smectite. Between $5.50 \mathrm{~m} 2.00 \mathrm{~m}$ the smectite is the main clay mineral, but with significant amounts of illite/mica and above $5.50 \mathrm{~m}$ occurs large increase in $\mathrm{K}$-feldspar and detrital mica. Studies in detail by X-ray diffraction (determination of the b-parameter) and microanalysis by wavelength dispersive X-ray spectroscopy have identified montmorillonite clay mineral as the smectite mineral specie.
\end{abstract}

Keywords: ceramic industry, clay minerals, mineralogical characterization.

\section{INTRODUÇÃO}

Atualmente a região sudeste do estado de Santa Catarina é um grande pólo produtor de cerâmicas de qualidade, com sofisticada tecnologia de produção [1]. Cerâmicas obtidas pelo processo de moagem a úmido são os artigos fabricados através da mistura de materiais divididos basicamente em plastificantes, estabilizantes e fundentes que numa proporção desejável são moídos e homogeneizados em moinhos de bola, em meio aquoso, posteriormente passando pela secagem e granulação da massa em um atomizador, moldagem e secagem das peças para posterior queima. As fábricas de cerâmicas possuem procedimentos de rotina deste processo de produção bastante moderno e automatizado. $\mathrm{Na}$ extração das matérias primas, porém, tem se utilizado de métodos de pesquisa muitas vezes acanhados e sem controle sistemático onde são comuns os procedimentos simples e empíricos. Ocorrendo falha no processo industrial, este pára, sendo então realizadas modificações nas quantidades das diferentes matérias primas da mistura em corpos de 
prova para verificação do comportamento físico, e a partir deste diagnóstico é reiniciado a produção. Como se tratam de matérias primas naturais, extraídas em grande quantidade e que apresentam variações mineralógicas importantes, podem trazer como conseqüência o comprometimento das características físicas das cerâmicas produzidas. Este processo tem levado a perdas enormes, passando a constituir também um problema ambiental. Com a motivação do aumento do potencial da atividade mineira pelo conhecimento das frentes de lavras, foram aplicadas técnicas para a caracterização mineralógica em detalhe de uma frente de lavra ativa da região. A mina se localiza em morro testemunho de depósitos sedimentares, que se projetam na planície costeira no sudeste catarinense próxima ao Rio Jundiá, no município de Turvo, SC (Fig. 1). Enquadra-se na carta geográfica folha Turvo SH-22-X-A-VI-4 (esc. 1/50.000) com coordenadas UTM de $6800901 \mathrm{~N}$ e $634118 \mathrm{E}$ com altitude da base da mina, coincidente à planície circundante, de $\sim 21 \mathrm{~m}$.

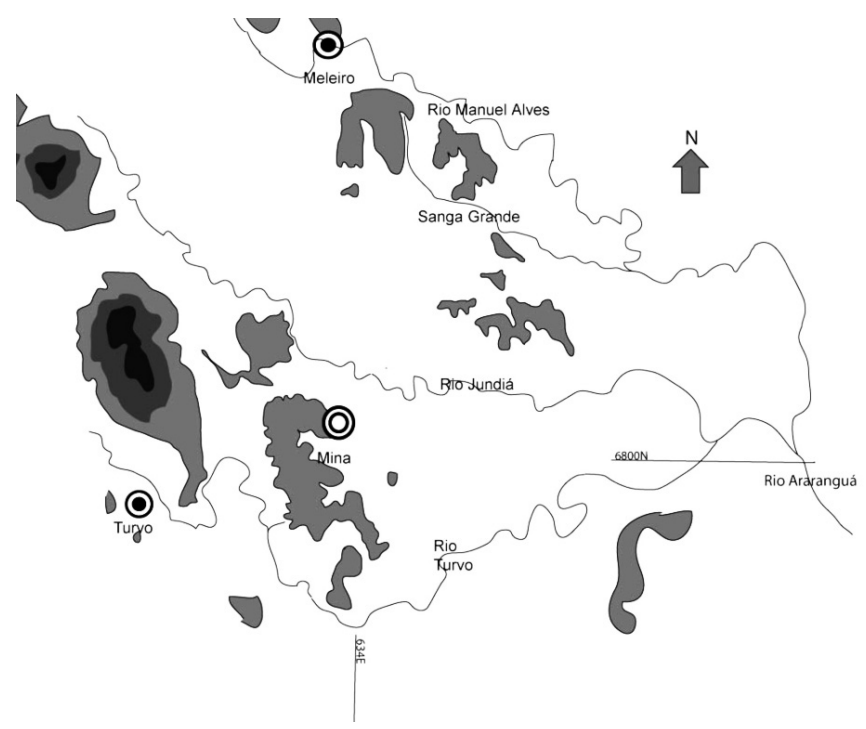

Figura 1: Mapa geológico simplificado do local da mina. Em preto Serra Geral, em cinza escuro Botucatu, em cinza claro Rio do Rasto e em branco os depósitos do Quaternário (modificado da CPRM [2]). [Figure 1: Simplified geological map of the mine location. Black: Serra Geral; dark gray: Botucatu; light gray: Rio do Rasto; and white: the Quaternary deposits (modified from CPRM [2]).]

\section{Aspectos geológicos}

Geologicamente estes depósitos posicionam-se na Formação Rio do Rasto no Grupo Passa Dois, na Bacia do Paraná do Permiano Superior, conforme coluna litoestratigráfica elaborada por Schneider (Fig. 2).

O Grupo Passa Dois compreende as Formações Serra Alta, Teresina e Rio do Rasto. São depósitos de sedimentos de origem dos granitóides que compunham os altos regionais num mar interior com vários pulsos de sequiência progradacional. A Formação Rio do Rasto é formada por uma espessa seqüência rítmica de arenitos, siltitos e folhelhos. Na porção basal, há uma total predominância de camadas

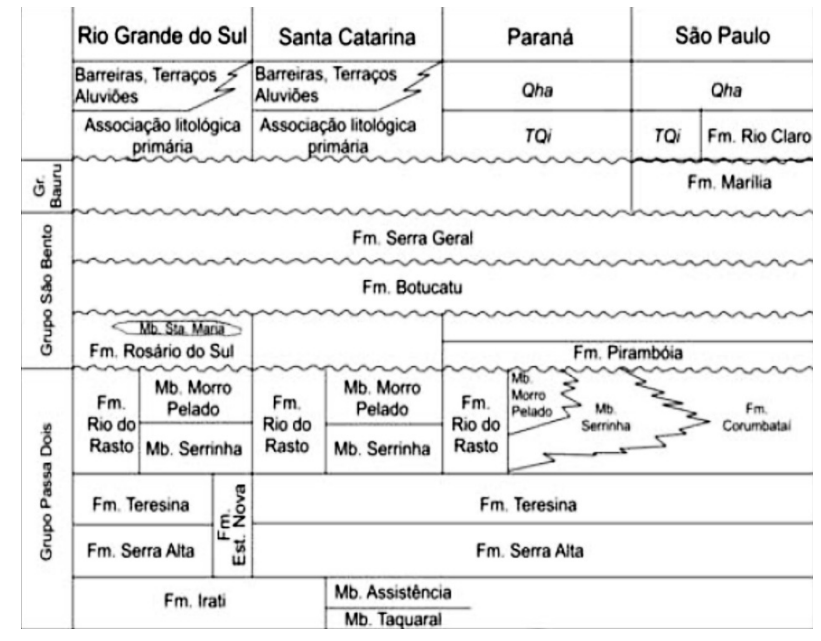

Figura 2: Coluna litoestratigráfica parcial da Bacia do Paraná [3]. [Figure 2: Partial lithostratigraphic column of the Paraná Basin [3].]

pelíticas. Os siltitos e folhelhos possuem alta fissilidade, laminação fina plano-paralela ou ondulada castanhoavermelhada. Os arenitos possuem granulação fina bem selecionada, cor cinza-avermelhado, aspecto maciço ou com estratificação acanalada, de pequeno porte. Pode apresentar intercalações de camadas ou lentes de calcário. As camadas possuem geometria tabular ou lenticular e a espessura das camadas de arenito é gradativamente maior da base para o topo da formação [4]. A rocha do presente estudo apresenta-se bastante litificada, possui estrutura maciça com fraturamento conchoidal centimétrico mais próximo à base e laminação plano-paralela incipiente para o topo, apresenta também finas camadas oxidadas e concreções ferríferas centimétricas. No topo apresenta camada centimétrica de tempestito e mais acima da área, onde foram coletadas as amostras, aparece uma camada de arenito fino de aproximadamente $0,80 \mathrm{~m}$.

\section{MATERIAIS E MÉTODOS}

Foram coletadas quatorze amostras na mina da base até o topo em uma coluna vertical de aproximadamente sete metros com uma distância de meio metro, em média, entre cada amostra da seguinte forma: quatro amostras do argilito maciço; uma amostra na lente de dez centímetros de espessura de siltito bastante poroso; três amostras de argilito maciço; uma amostra do argilito maciço que incorpora uma lente oxidada de um centímetro de espessura; três amostras de argilito maciço com fraturas subverticais; uma amostra do tempestito e uma amostra de argilito de estratificação plana paralela milimétrica a centimétrica. Foram escolhidas amostras sem alteração e com dimensões de cinco centímetros de diâmetro no mínimo.

A análise por microscopia ótica (MO) foi realizada em lâminas delgadas de duas amostras selecionadas do argilito e do siltito. A confecção das lâminas foi executada com a utilização de resina para possibilitar o corte da rocha. Este 
estudo possibilitou a observação das relações texturais, dimensões e cronologia das fases minerais, identificação das microestruturas dos constituintes detríticos e diagenéticos. Foi utilizado microscópio ótico com câmera fotográfica digital acoplada.

Para a caracterização mineralógica da rocha total pelo método do pó nas análises por difração de raios X (DRX), as amostras foram pulverizadas a 200 mesh e depositadas no porta-amostra de forma a ficar sem orientação preferencial dos grãos. Foi utilizada a faixa de $2^{\circ}$ até $75^{\circ}$. O passo foi de $0,02^{\circ}$ e o tempo de amostragem foi de $1 \mathrm{~s}$ por passo.

Para a caracterização mineralógica específica da fração < $4 \mu \mathrm{m}$ por DRX, foram preparadas lâminas orientadas a partir da desagregação das amostras no desagregador orbital em meio líquido (água deionizada) durante $24 \mathrm{~h}$ e posteriormente em ultra-som de ponteira por $5 \mathrm{~min}$. Posteriormente foi realizado o fracionamento granulométrico das amostras por decantação em água deionizada, com temperatura estabilizada para controlar a viscosidade. Neste processo foi acrescentado o defloculante hexametafosfato de sódio e, de acordo com a lei de Stokes, calculou-se o respectivo tempo de decantação das partículas maiores, ficando em suspensão a fração $<4 \mu \mathrm{m}$. O material em suspensão foi concentrado, pipetado e depositado em lâminas de vidro (porta-amostra) onde secaram lentamente na temperatura ambiente, fazendo com que as lamelas dos argilominerais ficassem preferencialmente orientadas com o eixo c ortogonal à lâmina. A lâmina de cada amostra foi analisada na condição natural, saturada com etileno-glicol (glicolada) e aquecida a $550{ }^{\circ} \mathrm{C}$ durante duas horas (calcinada). Foi utilizada a faixa de $2^{\circ}$ até $28^{\circ}$. O passo foi de $0,02^{\circ}$ e o tempo de amostragem foi $2 \mathrm{~s}$ nas análises das lâminas orientadas naturais e calcinadas e 2,5 s nas lâminas orientadas glicoladas [5]. A avaliação semiquantitativa da mineralogia da rocha total e da mineralogia específica da fração $<4 \mu \mathrm{m}$ foi obtido a partir dos difratogramas pelo cálculo da proporção das fases minerais presentes pela área do pico principal de cada fase mineral identificada: esmectita $\mathrm{d} \approx 15,00 \AA \AA$; ilita/mica $\mathrm{d} \approx$ $10,00 \AA ̊$ : plagioclásio d $\approx 3,19 \AA ̊$ : feldspato potássico d $\sim 3,23$ $\AA$; hematita $\mathrm{d} \sim 2,70 \AA$ a exceção do quartzo onde se utilizou o segundo pico mais intenso $\mathrm{d} \approx 4,26 \AA$. A determinação do parâmetro $b$ foi possível a partir da análise por DRX (pico hkl $=060$ ) da fração $<0,5 \mu \mathrm{m}$ obtido também pela metodologia acima com um tempo maior para decantação. O material em suspensão, depois de concentrado e seco, foi pulverizado e analisado de forma não orientada nas condições de passo de $0,02^{\circ}$ e o tempo de amostragem de $10 \mathrm{~s}$ por passo. As análises por DRX foram feitas com o difratômetro Siemens D5000 equipado com goniômetro $\theta-\theta$ com radiação $\mathrm{Cuk}_{\alpha}$, $40 \mathrm{kV}$ e $25 \mathrm{~mA}$.

Análises químicas por espectrometria de fluorescência de raios X (FRX) foram feitas (Rigaku RIX 2000) em amostras pulverizadas da rocha total e na fração $<4 \mu \mathrm{m}$ através da confecção de pastilhas fundidas. Foi misturada $1 \mathrm{~g}$ da amostra com $7 \mathrm{~g}$ de tetraborato de lítio, que são aquecidas a $1200{ }^{\circ} \mathrm{C}$ em cadinho de platina por 5 min e resfriadas rapidamente. As pastilhas são bombardeadas com raios $\mathrm{X}$ primários fazendo que a amostra emita raios $\mathrm{X}$ secundários de comprimentos de onda específicos onde o espectro corresponde ao elemento químico. Os resultados são apresentados na forma de percentagem de massa de seus óxidos que somados a perda ao fogo deve totalizar entre $98 \%$ a $102 \%$. A calcinação acontece a $1000{ }^{\circ} \mathrm{C}$ por $2 \mathrm{~h}$ para eliminação dos voláteis como $\mathrm{CO}_{2}, \mathrm{H}_{2} \mathrm{O}, \mathrm{S}, \mathrm{Cl}$ e F.

$\mathrm{O}$ microscópio eletrônico de varredura (MEV) Jeol JSM-6060 com $10 \mathrm{kV}$, resolução para imagem de ponto de $3,5 \mathrm{~nm}$, faixa de magnificação de 18 até 300.000 vezes, foi utilizado para obtenção de imagens de elétrons secundários dos fragmentos de 5 amostras representativas tendo sido as mesmas metalizadas com carbono e ouro. As análises permitiram obter imagens tridimensionais aparentes e a partir da forma foram identificados os minerais e a verificação das dimensões médias. Foi possível também observar a relação de crescimento de argilominerais nos poros e sobre grãos detríticos. Foi utilizada uma microssonda eletrônica (MSE) com WDS, Cameca SX50. As condições analíticas foram de $15 \mathrm{kV}, 10 \mathrm{nA}$, diâmetro do feixe $5 \mu \mathrm{m}$, tempo por ponto $10 \mathrm{~s}$ para realização de microanálises químicas pontuais em uma lâmina delgada polida e metalizada. A partir destas análises foram selecionadas e são apresentadas aquelas que atingiram os argilominerais esmectíticos.

\section{RESULTADOS E DISCUSSÃO}

As amostras das rochas da mina foram coletadas verticalmente até uma altura próxima a sete metros (Tabela I).

Foi identificada por microscopia óptica grande quantidade de minerais detríticos numa matriz predominantemente

Tabela I - Distribuição das diferentes camadas no perfil da mina onde foram coletadas as amostras.

[Table I - Distribution of different layers where samples were collected in the mine.]

\begin{tabular}{cl}
\hline Altura $(\mathrm{m})$ & \multicolumn{1}{c}{ Descrição da rocha. } \\
\hline 6,60 & Argilito com estratificação plano-paralela. \\
6,00 & Tempestito com espessura de $25 \mathrm{~cm}$. \\
5,45 & Argilito maciço. \\
5,05 & Argilito maciço. \\
4,65 & Argilito maciço. \\
4,25 & Argilito maciço com nível oxidado de \\
3,75 & A cm de espessura. \\
3,25 & Argilito maciço. \\
2,75 & Argilito maciço. \\
2,20 & Lente de siltito poroso de $10 \mathrm{~cm} \mathrm{de}$ \\
1,65 & espessura. \\
1,15 & Argilito maciço. \\
0,65 & Argilito maciço. \\
0,15 & Argilito maciço. \\
\hline
\end{tabular}


argilosa. Grãos detríticos aparecem com tamanhos entre 30 e $50 \mu \mathrm{m}$ e são representados por micas, quartzo, feldspato potássico, plagioclásio, hematita, esfeno e outros minerais pesados e apresentam-se muito angulosos e com baixa esfericidade (Fig. 3).

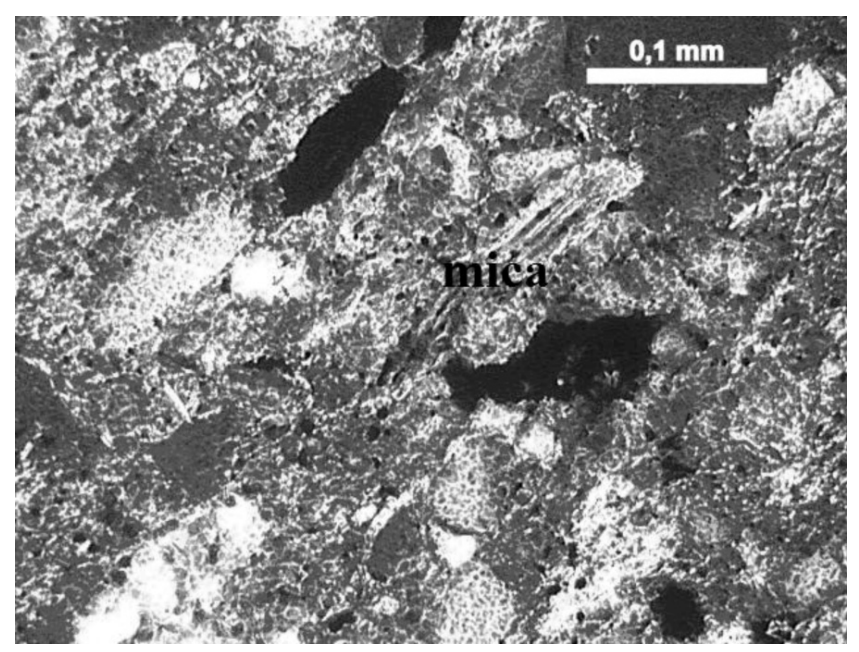

Figura 3: Fotomicrografia onde aparece mica detrítica com pequena deformação.

[Figure 3: Photomicrograph which appears detrital mica with small deformation.]

A mineralogia é típica de granitóides, possivelmente proveniente dos altos do embasamento presentes mais ao norte a partir do município de Criciúma. A rocha apresentase com porosidade predominantemente baixa em todo o afloramento, porém é localmente grande no nível síltico. A mineralogia identificada a partir da análise por difração de raios X (Fig. 4) é constituída por esmectita, ilita/mica, quartzo, feldspato potássico, plagioclásio, além de hematita contida basicamente nas concreções.

A partir da avaliação semiquantitativa por DRX, verifica-

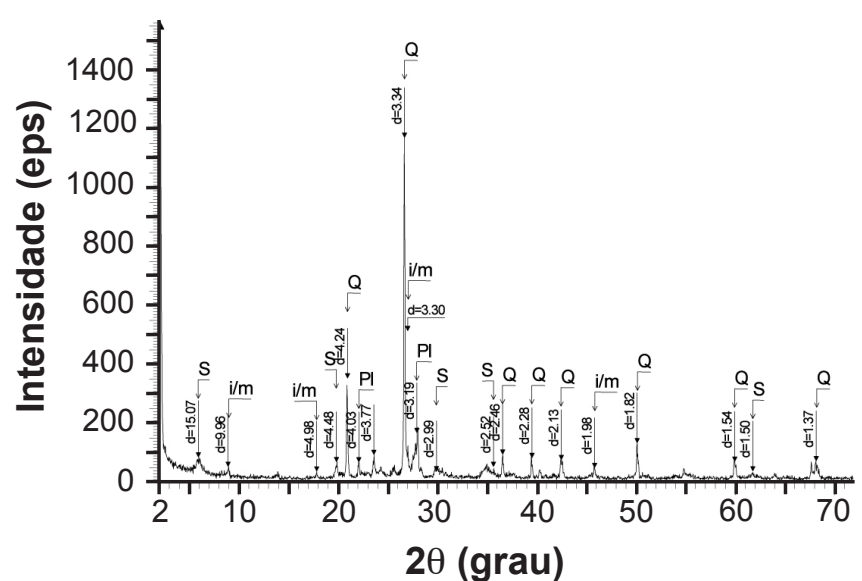

Figura 4: Difratograma de raios $\mathrm{X}$ da rocha total: (S) esmectita, (i/m) ilita/mica, $(\mathrm{Q})$ quatzo e $(\mathrm{Pl})$ plagioclásio.

[Figure 4: XRD pattern of the raw materials: (S) smectite, (i/m) illite/mica, $(Q)$ quartz and (Pl) plagioclase.]

se a variação dos componentes com o aumento da proporção de feldspato potássico para o topo e aumento da esmectita para a base, os demais minerais possuem grande oscilação (Tabela II).

Nas análises por DRX das lâminas orientadas na fração $<4 \mu \mathrm{m}$, em todas as amostras foi identificada a esmectita (cálcica) que na forma natural apresenta o pico $(\mathrm{hkl}=001)$ com $\mathrm{d} \sim 15 \AA$, saturadas com etilenoglicol expandindo-se para $\mathrm{d} \sim 17 \AA$. Na forma calcinada colapsa para $\mathrm{d} \sim 10 \AA$ (Fig. 5).

Nesta análise também foi identificado que o pico de d $10 \AA$, da ilita/mica, não se altera na análise glicolada indicando ausência de fases expansíveis e não colapsa na análise da amostra quando calcinada [6]. A partir da interpretação das análises na fração $<4 \mu \mathrm{m}$ foi realizada a avaliação semiquantitativa (Tabela III).

Tabela II - Mineralogia da rocha total normatizada para $100 \%$ obtida pela avaliação semiquantitativa por DRX. [Table II - Mineralogy of raw material normalized to 100\% obtained after semiquantitative XRD.]

\begin{tabular}{lcccccc}
\hline Altura $(\mathrm{m})$ & esmectita & ilita/mica & quartzo & $\begin{array}{c}\text { feldspato } \\
\text { potássico }\end{array}$ & plagioclásio & hematita \\
\hline 6,60 & 3 & 14 & 19 & 39 & 26 & 0 \\
6,00 & 1 & 2 & 37 & 24 & 36 & 0 \\
5,45 & 10 & 6 & 46 & 20 & 18 & 0 \\
5,05 & 8 & 6 & 31 & 27 & 17 & 12 \\
4,65 & 8 & 9 & 30 & 28 & 26 & 0 \\
4,25 & 1 & 3 & 12 & 16 & 42 & 27 \\
3,75 & 7 & 6 & 41 & 32 & 13 & 2 \\
3,25 & 4 & 5 & 31 & 45 & 14 & 0 \\
2,75 & 18 & 8 & 32 & 22 & 20 & 0 \\
2,20 & 8 & 3 & 29 & 0 & 60 & 0 \\
1,65 & 12 & 9 & 25 & 28 & 25 & 0 \\
1,15 & 14 & 5 & 37 & 16 & 29 & 0 \\
0,65 & 15 & 5 & 39 & 12 & 29 & 0 \\
0,15 & 19 & 6 & 27 & 8 & 40 & \\
\hline
\end{tabular}




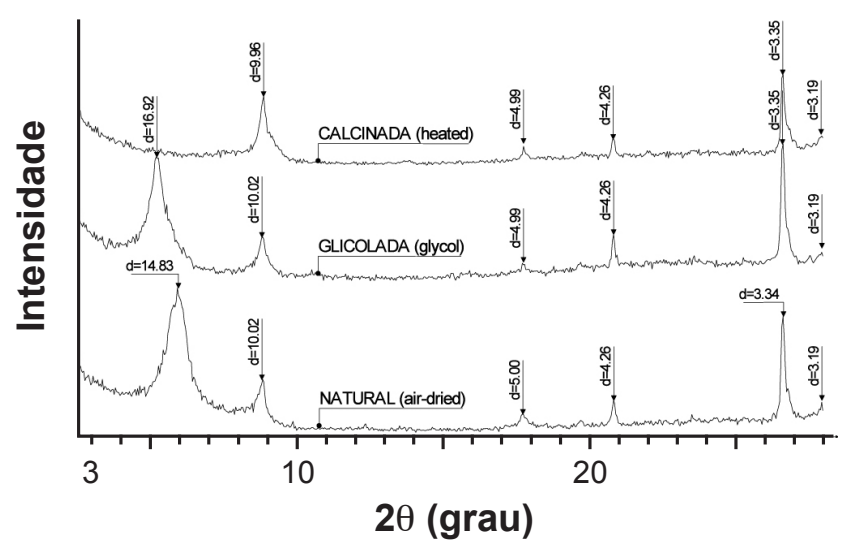

Figura 5: Difratogramas de raios $X$ da fração $<4 \mu \mathrm{m}$ na forma orientada natural, glicolada e calcinada (aquecida).

[Figure 5: XRD patterns of clay-fraction $(<4 \mu \mathrm{m})$ in oriented airdried, ethylene glycol-solvated and heated.]

Por meio dos resultados da Tabela III foi possível caracterizar três níveis distintos (Fig. 6).

O primeiro nível correspondente ao pacote de argilito maciço, da base até próximo a 2,00 m, onde ocorre a lente de siltito, com a predominância de esmectita; o segundo nível entre $2,00 \mathrm{~m}$ e $5,50 \mathrm{~m}$, correspondendo também a um pacote de argilito maciço onde a esmectita e ilita são predominantes havendo diminuição de esmectita e do quartzo em relação ao primeiro nível; o terceiro e último nível acima de 5,50 m onde o argilito se apresenta com intraclastos no tempestito e com estratificação planoparalela logo acima, onde temos uma diminuição da esmectita e um aumento relativo de quartzo e feldspato

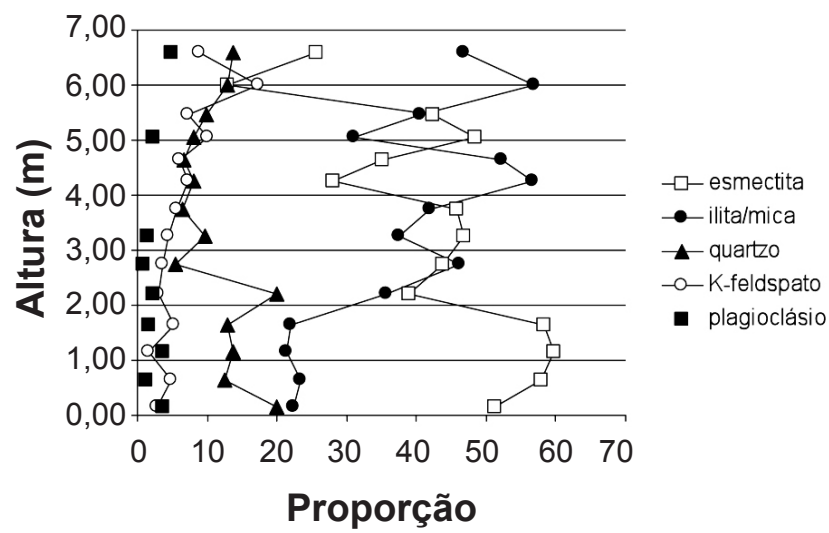

Figura 6: Variação da proporção dos minerais da fração $<4 \mu \mathrm{m}$ em relação à altura do perfil.

[Figure 6: Variation of the proportion of minerals in the fraction $<$ 4 um in the profile.]

potássico assim como grande quantidade de mica detrítica identificada ao MO e ao MEV. Esta camada é considerada estéril pela mineradora devido possivelmente à presença de mica que dá característica refratária à massa cerâmica .

Os resultados das análises químicas por FRX da rocha total (Tabela IV) e da fração $<4 \mu \mathrm{m}$ (Tabela V) mostram coerência com as variações nas concentrações mineralógicas determinadas por MO e DRX. A perda ao fogo (PF) foi baixa sugerindo ser grande a proporção do material detrítico, inclusive da mica em relação a ilita.

Das análises químicas destaca-se o aumento do alumínio na fração devido à concentração de argilominerais e o aumento do potássio para o topo da coluna acompanhando

Tabela III - Mineralogia da fração $<4 \mu \mathrm{m}$ normatizada para $100 \%$ obtida pela avaliação semiquantitativa por DRX.

[Table III - Mineralogy of fraction < $4 \mu \mathrm{m}$ normalized to $100 \%$ obtained after semiquantitative XRD.]

\begin{tabular}{cccccc}
\hline Altura $(\mathrm{m})$ & esmectita & ilita/mica & quartzo & feldspato potassio & plagioclásio \\
\hline 6,60 & 26 & 47 & 14 & 9 & 5 \\
6,00 & 13 & 57 & 13 & 17 & 0 \\
5,45 & 42 & 41 & 10 & 7 & 0 \\
5,05 & 48 & 31 & 8 & 10 & 2 \\
4,65 & 35 & 52 & 7 & 6 & 0 \\
4,25 & 28 & 57 & 8 & 7 & 0 \\
3,75 & 46 & 42 & 7 & 6 & 0 \\
3,25 & 47 & 37 & 10 & 5 & 1 \\
2,75 & 44 & 46 & 5 & 4 & 1 \\
2,20 & 39 & 36 & 20 & 3 & 2 \\
1,65 & 58 & 22 & 13 & 5 & 2 \\
1,15 & 60 & 21 & 14 & 2 & 4 \\
0,65 & 58 & 23 & 13 & 5 & 1 \\
0,15 & 51 & 22 & 20 & 3 & 4 \\
\hline
\end{tabular}


Tabela IV - Composição química da rocha total.

[Table IV - Chemical composition of the raw materials.]

\begin{tabular}{ccccccccccc}
\hline Altura $(\mathrm{m})$ & $\mathrm{SiO}_{2}$ & $\mathrm{Al}_{2} \mathrm{O}_{3}$ & $\mathrm{TiO}_{2}$ & $\mathrm{Fe}_{2} \mathrm{O}_{3}$ & $\mathrm{MnO}$ & $\mathrm{MgO}$ & $\mathrm{CaO}$ & $\mathrm{Na}_{2} \mathrm{O}$ & $\mathrm{K}_{2} \mathrm{O}$ & $\mathrm{PF}$ \\
\hline 6,60 & 69,8 & 16,2 & 0,5 & 3,0 & 0,0 & 1,3 & 0,3 & 0,6 & 5,1 & 3,2 \\
6,00 & 71,0 & 14,4 & 0,6 & 4,4 & 0,0 & 1,3 & 0,2 & 0,0 & 5,3 & 3,7 \\
5,45 & 68,8 & 15,0 & 0,6 & 4,1 & 0,1 & 1,6 & 0,5 & 0,5 & 5,6 & 3,5 \\
5,05 & 70,6 & 14,8 & 0,6 & 3,9 & 0,0 & 1,4 & 0,5 & 0,7 & 5,6 & 3,1 \\
4,65 & 69,8 & 14,9 & 0,6 & 4,2 & 0,0 & 1,6 & 0,5 & 0,6 & 5,7 & 3,3 \\
4,25 & 69,2 & 14,8 & 0,6 & 5,3 & 0,0 & 1,5 & 0,4 & 0,5 & 5,4 & 3,0 \\
3,75 & 70,5 & 15,2 & 0,6 & 4,3 & 0,0 & 1,5 & 0,4 & 0,3 & 5,5 & 3,2 \\
3,25 & 68,6 & 15,3 & 0,6 & 4,7 & 0,0 & 1,6 & 0,5 & 0,4 & 5,6 & 3,3 \\
2,75 & 67,0 & 15,4 & 0,6 & 5,0 & 0,0 & 2,1 & 0,6 & 0,6 & 4,7 & 4,5 \\
2,20 & 71,5 & 13,9 & 0,6 & 4,0 & 0,2 & 1,6 & 0,7 & 1,4 & 3,4 & 3,5 \\
1,65 & 69,3 & 14,5 & 0,6 & 3,9 & 0,0 & 1,8 & 0,8 & 0,8 & 4,0 & 4,2 \\
1,15 & 69,2 & 15,0 & 0,6 & 4,4 & 0,0 & 1,4 & 0,4 & 0,4 & 5,5 & 3,2 \\
0,65 & 70,6 & 14,5 & 0,6 & 4,1 & 0,0 & 2,0 & 0,8 & 1,0 & 3,4 & 3,5 \\
0,15 & 69,8 & 14,1 & 0,6 & 3,8 & 0,0 & 1,9 & 0,8 & 1,1 & 3,2 & 3,7 \\
\hline
\end{tabular}

Tabela V - Composição química da fração $<4 \mu \mathrm{m}$.

[Table V-Chemical composition of fraction $<4 \mu \mathrm{m}$.]

\begin{tabular}{ccccccccccc}
\hline Altura (m) & $\mathrm{SiO}_{2}$ & $\mathrm{Al}_{2} \mathrm{O}_{3}$ & $\mathrm{TiO}_{2}$ & $\mathrm{Fe}_{2} \mathrm{O}_{3}$ & $\mathrm{MnO}$ & $\mathrm{MgO}$ & $\mathrm{CaO}$ & $\mathrm{Na}_{2} \mathrm{O}$ & $\mathrm{K}_{2} \mathrm{O}$ & $\mathrm{PF}$ \\
\hline 6,60 & 59,0 & 19,7 & 0,7 & 4,7 & 0,0 & 2,7 & 0,3 & 0,1 & 7,2 & 5,1 \\
6,00 & 59,6 & 19,6 & 0,7 & 3,8 & 0,1 & 1,7 & 0,2 & nd & 7,5 & 5,2 \\
5,45 & 59,3 & 20,0 & 0,8 & 5,1 & 0,1 & 3,3 & 0,5 & 0,0 & 6,9 & 5,0 \\
5,05 & 60,1 & 18,6 & 0,7 & 5,0 & 0,1 & 3,0 & 0,5 & nd & 7,1 & 5,2 \\
4,65 & 59,0 & 18,0 & 0,8 & 4,8 & 0,1 & 2,8 & 0,4 & 0,1 & 7,2 & 6,1 \\
4,25 & 52,2 & 18,4 & 0,8 & 13,4 & 0,1 & 1,8 & 0,4 & 0,2 & 5,4 & 5,4 \\
3,75 & 57,5 & 20,6 & 0,8 & 5,0 & 0,0 & 3,3 & 0,5 & nd & 6,8 & 5,6 \\
3,25 & 62,0 & 17,4 & 0,7 & 5,1 & 0,0 & 2,3 & 0,4 & 0,1 & 6,3 & 4,5 \\
2,20 & 58,4 & 17,5 & 0,8 & 5,3 & 0,3 & 3,7 & 0,5 & 0,8 & 5,3 & 7,2 \\
1,15 & 59,7 & 16,5 & 0,7 & 5,0 & 0,0 & 4,5 & 0,8 & 0,5 & 4,0 & 7,8 \\
0,65 & 61,9 & 16,4 & 0,7 & 4,9 & 0,0 & 3,6 & 0,8 & 0,2 & 3,7 & 6,9 \\
0,15 & 61,6 & 16,2 & 0,7 & 4,8 & 0,0 & 3,5 & 0,8 & 0,2 & 3,6 & 7,1 \\
\hline
\end{tabular}

o aumento do feldspato potássico e de ilita/mica. A sílica diminui na fração $<4 \mu \mathrm{m}$ em razão da diminuição de quartzo e feldspatos. As análises de imagens de elétrons secundários realizadas no MEV permitiram identificar o crescimento de esmectita sobre um grão de feldspato detrítico (Fig. 7) e a presença acentuada de mica detrítica, confirmando os dados observados ao MO e através das análises de DRX (Fig. 8).

A esmectita está presente, pois retrata contribuição típica das áreas fontes de clima árido ou semiárido de condições pouco lixiviantes [7]. Na análise do parâmetro b foi possível a identificação da montmorilonita (esmectita dioctaédrica) como argilomineral predominante na fração fina (Figs. 9 e 10).

Verifica-se também que aparece elevada proporção ilita/mica (dioctaédrica), possivelmente a neoformação de ilita nas bordas dos grãos, como pode ser visto na imagem do MEV na Fig. 7. A partir de seis análises por MSE foi possível calcular a fórmula estrutural média da montmorilonita (base de 11 oxigênios e $\mathrm{Fe}$ total $=\mathrm{Fe}^{2+}$ ): $\mathrm{Ca}_{0,22(0,08)} \mathrm{Na}_{0,12(0,08)} \mathrm{K}_{0,13(0,03)}\left(\mathrm{Al}_{1,45(0,06)} \mathrm{Mg}_{0,39(0,05)} \mathrm{Fe}^{2+}{ }_{0,13(0,04)}\right)$ $\left(\mathrm{Si}_{3,99(0,04)} \mathrm{Al}_{0,02(0,02)}\right) \mathrm{O}_{10}(\mathrm{OH})_{2}$
Os valores dos índices entre parênteses é o desvio padrão da média das análises. A compensação de carga, principalmente gerada pela presença de $\mathrm{Mg}^{2+}\left(\mathrm{Fe}^{2+}\right)$ no octaedro e mais discretamente $\mathrm{Al}^{3+}$ no tetraedro, indica ser o argilomineral esmectítico uma montmorilonita onde o cálcio é o cátion interlamelar predominante [4].

\section{CONCLUSÕES}

Os resultados obtidos mostram que as técnicas de microscopia óptica, difração de raios $X$, fluorescência de raios $X$, microscopia eletrônica de varredura e microssonda eletrônica são adequadas para a análise das amostras, em especial na identificação dos argilominerais. As análises mostram a existência de grande variação da composição mineralógica verticalmente numa mesma frente de lavra. A existência de três níveis distintos, onde existe a predominância de montmorilonita e alguma ilita/mica nos dois primeiros níveis conferindo uma característica a matéria prima mais homogênea dando maior plasticidade à massa cerâmica. Acima de 5,50 m há uma queda no teor 


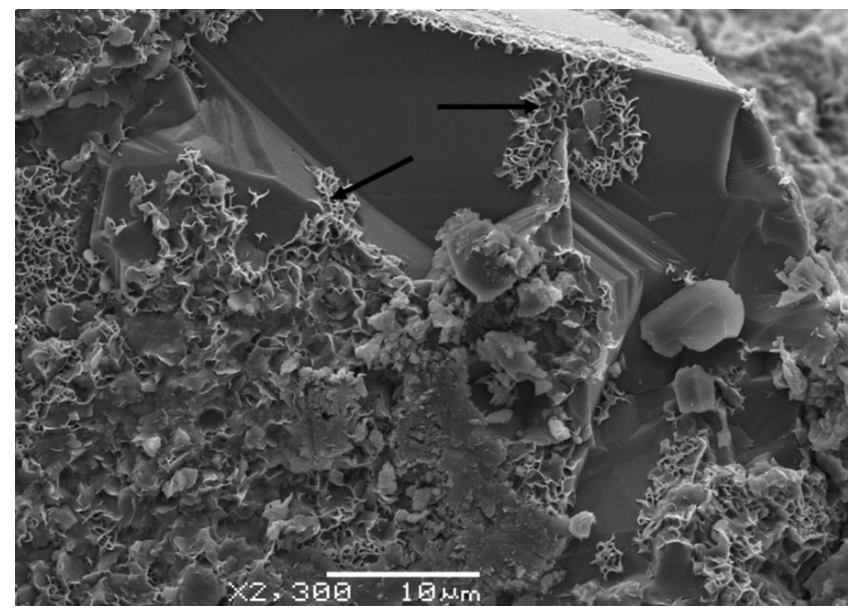

Figura 7: Imagem de microscopia eletrônica de varredura: crescimento de esmectita sobre um grão de feldspato detrítico (setas). [Figure 7: Scanning electron microscope image: growth of smectite on a grain of detrital feldspar (arrows).]

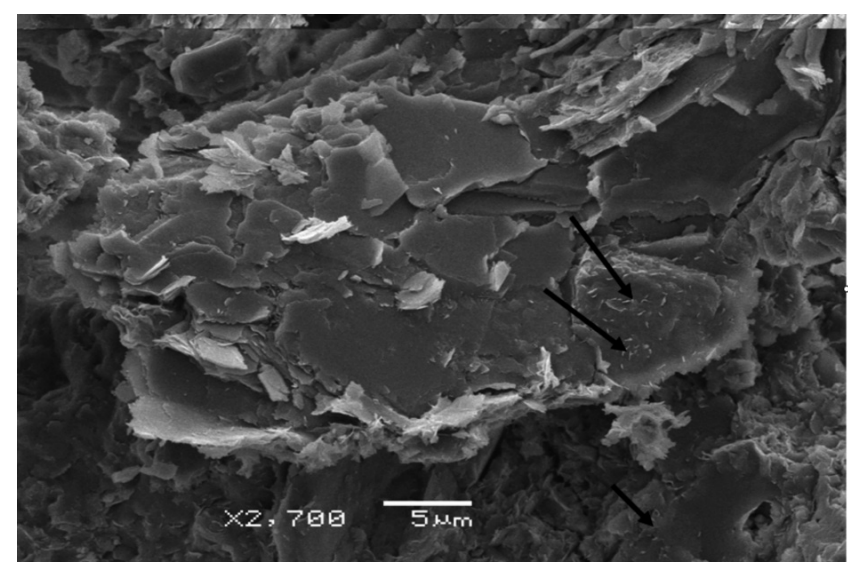

Figura 8: Imagem do MEV mostrando mica detrítica com crescimento incipiente de argilomineral sobre o grão (setas).

[Figure 8: Scanning electron microscope image showing detrital mica with incipient growth of clay minerals on the grain (arrows).]

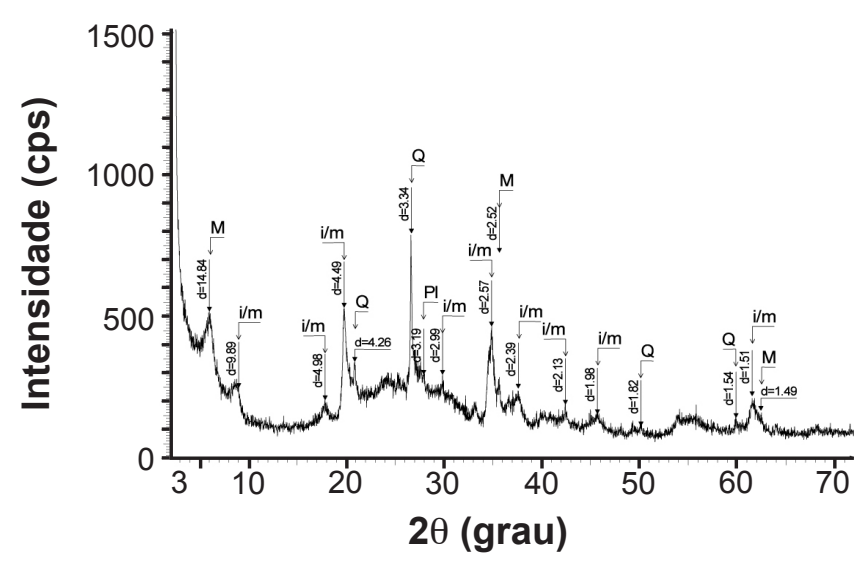

Figura 9: Difratograma de raios $\mathrm{X}$ da fração $<0,5 \mu \mathrm{m}$ na forma pulverizada e sem orientação: montmorilonita (M), ilita/mica (i/m) (dioctaédrica), plagioclásio $(\mathrm{Pl})$ e quartzo $(\mathrm{Q})$.

[Figure 9: XRD pattern of the fraction $<0.5 \mu \mathrm{m}$ of randomly oriented powders: montmorillonite $(M)$, illite/mica (i/m) (dioctahedral), plagioclase $(\mathrm{Pl})$ and quartz (Q).]

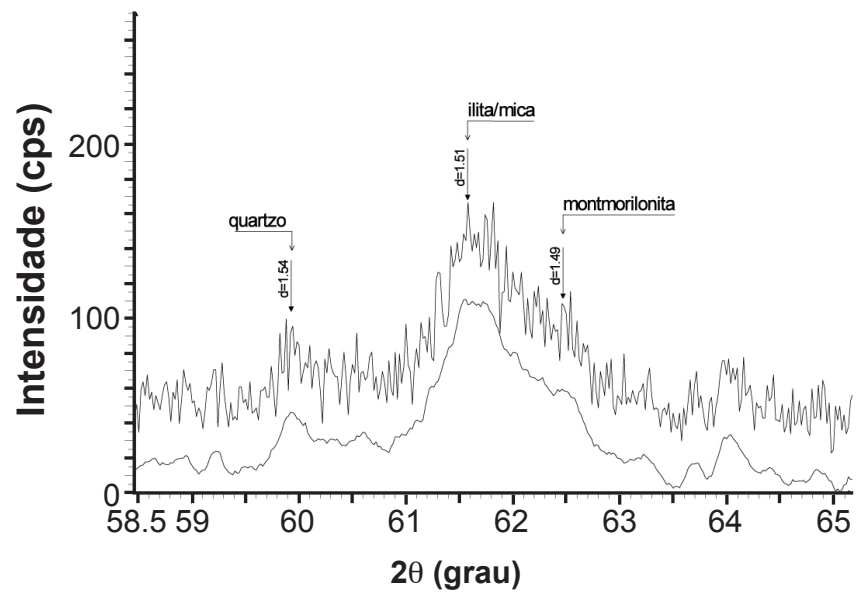

Figura 10: Difratograma de raios $X$ do parâmetro b da fração < $0,5 \mu \mathrm{m}$ na forma pulverizada e sem orientação: montmorilonita (esmectita dioctaédrica como espécie mineral).

[Figure 10: XRD pattern of the $b$ - parameter in the fraction $<0.5$ $\mu \mathrm{m}$ of randomly oriented powder: montmorillonite (dioctahedral smectite mineral species).]

de montmorilonita, um relativo aumento de quartzo e feldspato potássico e grande quantidade de mica detrítica com variações nas diferentes camadas. Desta maneira, a matéria prima é mais heterogênea e de características mais refratárias que fundentes com o aumento de mica detrítica. Como deve haver controle da homogeneidade nos lotes da matéria prima explorada destinada à produção cerâmica, configura-se assim a importância de amostragem e caracterização mineralógica e química, para o bom rendimento da mineração, sendo fundamental o controle geológico, mineralógico e geoquímico.

\section{REFERÊNCIAS}

[1] A. P. F. Gorini, A. R. Correa, Cerâmica para Revestimentos, BNDES Setorial, Rio de Janeiro, RJ, 10 (1999) 226.

[2] CPRM, http//mapoteca.cprm.gov.br/programas/ template.

php, Brasil (2007)

[3] R. L. Schneider, H. Mühlmann, E. Tommasi, R. A. Medeiros, R. F. Daemon, A. A. Nogueira, "Revisão estratigráfica da Bacia do Paraná", Anais Cong. Bras. Geologia 28 (1974) 43.

[4] R. L. Schneider, H. Mühlmann, E. Tommasi, R. A. Medeiros, R. F. Daemon, A. A. Nogueira, "Revisão estratigráfica da Bacia do Paraná”, Anais Cong. Bras. Geologia 28 (1974) 56.

[5] D. B. Alves, "Desenvolvimento de metodologia de preparação de amostras para análise difratométrica de argilominerais no centro de pesquisas da Petrobrás", Rio de Janeiro, RJ, 1, 2 (1987) 157-175.

[6] G. W. Brindley, G. Brown, "Crystal structures of clay minerals and their X-ray identification", Londres, Inglaterra (1980) 495. 
[7] A. N. Ramos, M. L. L. Formoso, "Argilominerais de rochas sedimentares da Bacia do Paraná", CENPES, Rio de Janeiro, RJ (1975) 43.

(Rec. 28/01/2010, Rev. 24/02/2010, Ac. 27/03/2010) 